\title{
In Vitro Effect of Ozone in Phagocytic Function of Leucocytes in Peripheral Blood.
}

\author{
Jacqueline Diaz-Luis', Silvia Menendez-Cepero², Arturo Diaz-Luis, Yudenia \\ Ascanio-Garcia
}

\author{
${ }^{1}$ Roberto Rodriguez-Fernandez Hospital, Moron, Ciego de Avila, Cuba. \\ ${ }^{2}$ Centro Prodanza, Habana, Cuba.
}

doi: 10.7203/jo3t.1.1.2015.10627

Received: October, 2015

Published: December 2015

\section{ABSTRACT}

Introduction: The ozone immune modulation is based on its effect on the immune system and oxidative metabolism. When whole human blood is exposed to the appropriate ozone doses, we can observe in the cells different biochemical reactions that in turn are able to improve the immunity mechanism. Objectives: The aim of this in vitro experimental study was to evaluate the effect of ozone on blood phagocytosis. Methods: Blood samples of $30 \mathrm{~mL}$ were taken from five healthy male blood donors in the morning, and were subdivided in 6 glass tubes of $5 \mathrm{~mL}$ each (control, oxygen and 4 ozone groups). A volume of $5 \mathrm{~mL}$ ozone/ oxygen mixture at different ozone concentrations $(10,20,40$ and $80 \mu \mathrm{g} / \mathrm{mL})$ was collected with glass syringes. There after the gas was immediately bubbled in the blood samples. Syringes were slowly but continuously mixed in shaker with stirring, during $10 \mathrm{~min}$ allowing a complete mixing of the liquid-gas phases with minimal foaming. Two of the above blood samples were used as controls: the first sample blood and the second blood treated with oxygen only. Phagocytic cell function was assessed by direct microscopic Baehner method. Results: The results were analyzed by paired T test; significance was defined as a $p$ value less than 0.05. Results: After ozonation, phagocytic function increase with significant differences in comparison with controls groups $(p=0.04)$. Respect to the ozone concentrations, the phagocytic function increased at $20 \mu \mathrm{g} / \mathrm{mL}$ and even more at $40 \mu \mathrm{g} / \mathrm{mL}$, but decrease with $80 \mu \mathrm{g} / \mathrm{mL}$. However, there were no significant differences in phagocytic function in the blood exposed to $10 \mu \mathrm{g} / \mathrm{mL}$ in comparison with controls. Conclusion: Ozone may stimulate the phagocytic function of the peripheral blood cells in a dose-dependent fashion.

Keywords: Ozone, Immune Modulation, Oxidative Metabolism, Biochemical Reaction, Immunity Mechanism, Phagocytic Function

\section{INTRODUCTION}

The classical method of exposing ex vivo human blood to ozone-oxygen for few minutes in a gas resistant bottle was published for the first time by Wolff in 1974 (1). On the other hand, human blood exposes ex vivo to ozone has been explicitly formulated by Professor Velio Bocci et al. in several investigations $(2,3)$.

Ozone is more soluble that oxygen and reacts immediately with a variety of polyunsaturated fatty acids ( PUFA ) bound to albumin, plasmatic antioxidants such as uric acid, ascorbic acid, transferrin, vitamin $\mathrm{E}$, reduced glutathione (GSH),

\section{Authors Information}

\section{E-mail address: jdiaz@hgm.cav.sld.cu}

proteins, glucose, ceruloplasmin, sulfhydryl groups and albumin itself, expressed as total antioxidant status ( 4 ).

The PUFA represent elective substrates and are mostly albumin-bound. Peroxidation of PUFA leads to the formation of $\alpha$-hidroxy-hidroperoxides, $\mathrm{H}_{2} \mathrm{O}_{2}$ and 4-hidroxynonenal. All of these reactions happen in a few seconds. Ozone dissolves in the plasmatic water and instantly reacts, producing a rather small depletion of hydrosoluble antioxidant and the simultaneous increase of plasmatic ROS and $\operatorname{LOP}(4,5)$.

The $\mathrm{H}_{2} \mathrm{O}_{2}$ produced during an initial short period of time, in mixing blood with the gas ex vivo, diffuses freely into all blood cells. The establishment of a dynamic and transitory $\mathrm{H}_{2} \mathrm{O}_{2}$ gradient between the plasma and the cytoplasmic water of blood cells make this oxidant very early effector (3). The smartness of this event is that even if the $\mathrm{H}_{2} \mathrm{O}_{2}$ 
concentration is very small, it is enough to trigger crucial biochemical reaction without toxicity. Indeed, the internal cell environment rich in antioxidants [reduced glutathione (GSH), catalase, glutathione peroxidase (GSH-Px), superoxide dismutase] protect the cells (6) from any damage. This is an important, controlled and transient oxidative stress able to activate the biological environment, without concomitant toxicity (7).

In the cytoplasm, the $\mathrm{H}_{2} \mathrm{O}_{2}$ activates a tyrosinekinase that produces $\mathrm{IkB}$ phosphorylation, one of the trimeric components at rest of the ubiquitous transcription factor denominated NF-kB. The phosphorylated IkB detaches from the trimmer and it is broken down in the proteasome. The remaining heterodimer p50-p65 is transferred into the nucleus, where it can activate about 100 genes, upregulating the synthesis of acute-phase proteins and several pro inflammatory cytokines (IFN- $\sigma, \mathrm{TNF}-\alpha$, IL-8) $(8,9)$.

Basically the $\mathrm{H}_{2} \mathrm{O}_{2}$ is the trigger as the activation is related to a cysteine oxidation acting on the peripheral blood cells, endothelial cells and erythrocytes. This biochemical way is modulated by antioxidants, as intracellular reduced glutathione, ascorbic acid, glutathione peroxidase and catalase. As a consequence, too low $\mathrm{O}_{3}$ concentrations generate very low levels of $\mathrm{H}_{2} \mathrm{O}_{2}$ unable to activate NF-kB and very high $\mathrm{O}_{3}$ concentration produce high levels of $\mathrm{H}_{2} \mathrm{O}_{2}$ that by overwhelming intracellular antioxidants lead to cell damage $(2,3)$. For that reason, ozone dose must be compatible with antioxidant capability of the blood. The ozone dose is within a well-defined level, experimentally determined $(10-80 \mu \mathrm{g} / \mathrm{mL}$ of gas per $\mathrm{mL}$ of blood). There is only a transitory decrease (no more than 25\%) of the potent antioxidant capacity of plasma, fully reconstituted within 20 min owing to the efficiency of the redox system. An ozone dose below $10 \mu \mathrm{g} / \mathrm{mL}$ of gas per $\mathrm{mL}$ of blood, in most cases is biologically ineffective because the ozone dose is totally neutralized by the plasma antioxidants (placebo effect). On the other hand, a higher dose of the therapeutic one can be toxic (2).

In previous experiments were demonstrated that erythrocytes washed with physiological saline solution, suspended in phosphate buffered physiological saline and exposed to the mixture of $\mathrm{O}_{3} / \mathrm{O}_{2}$, increased the sensitivity to the ozone oxidative action. These conditions can produce cellular membrane rupture, metahemoglobin formation and enzymes inactivation, since the membrane was deprived of the albumin's protection
(10). The peripheral blood mononuclear cells exposition to ozone, during 48 and 72 hours, has demonstrated an intimate relation among the production of cytokines and ozone concentration. The response of mononuclear cells to ozone is quite different depending upon whether they had been exposed in whole blood, or have been isolated, washed and suspended in 10\% fetal calf's serum, with the substantial deprivation of antioxidant system that make peripheral blood mononuclear cells very sensitive to ozone and progressively depress cell proliferation (11). These data are important to view the toxicity of ozone on the cells incubated in culture without antioxidants (1).

In the whole blood incubated with ozone, is induced the immunocompetent cells activation directly. The products of the $\mathrm{O}_{3}$ reaction, especially the $\mathrm{H}_{2} \mathrm{O}_{2}$ and the lipoperoxides, behave as biological marker associated with the immune system's improvement. Those compounds enhanced the neutrophils activation and phagocytic activity (12).

The phagocytes are cells that have specialized phagocytic functions, primarily macrophages and neutrophils, are the first line of defense against microbes that break epithelial barriers or enter the circulation. The neutrophils travel through the blood throughout the organism, in search of pathogenic invaders. It is the phagocyte more common of the blood, representing among the 50\% and $60 \%$ of the total leukocytes (13).

The phagocytosis causes the death of microbes by activated phagocytes. The neutrophil kills phagocytized microbes by action of anti-microbial molecules in phagolysosomes. First, microbe or particle binds to receptor, and are internalized into fagosome, which fuse with lysosome to form phagolysosomes, where the microbes are killed by reactive oxygen species (ROS) and nitrogen intermediates and proteolytic enzyme. These processes, produced during the phagocytosis, describe a metabolic pathway whose role is to produce three types of anti-microbial mechanisms: ROS, nitric oxide and enzymes (elastase and cathepsin G) (13).

The neutrophils convert molecular oxygen into ROS, which are highly reactive oxidizing agents that destroy microbes, particles and other cells. The primary free-radical-generating system is the phagocyte oxidase system. Phagocyte oxidase is a multisubunit enzyme that is assembled in activated phagocyte mainly in the phagolysosomal membrane. Phagocyte oxidase is induced and activated by main stimuli, the function of this 
enzyme is to reduce molecular oxygen into ROS, such as superoxide anion, acting nicotinamide adenine dinucleotide phosphate (NADPH) as a cofactor. Superoxide may inactivate critical metabolic enzymes, initiate lipid peroxidation and liberate redox-active iron, which allows the generation of indiscriminate oxidants such as the hydroxyl radical. Also, superoxide is enzymatically dismutated into $\mathrm{H}_{2} \mathrm{O}_{2}$ (by the superoxide dismutase) which is used by the enzyme myeloperoxidase to convert normally a reactive halide ion into reactive hypohalous acids that are toxic for bacteria. It is called respiratory burst. This process is to supply reactive agents that are very important to microorganism destruction $(13,14)$.

The phagocytes produce $\mathrm{H}_{2} \mathrm{O}_{2}$ as a first line of defense against invading organism like viruses, bacteria and parasites. It is lethal for the bacterial cells; killing bacteria is important as it inhibits their ability to cause diseases. $\mathrm{H}_{2} \mathrm{O}_{2}$ is responsible of the cellular wall lyses. Also, it is critical in order to activate kinases and transcription factors that induce cytokines and growth factors synthesis. It is involved in all of life vital processes (14).

With the aim to imitate in vitro all the biological events that occur during ozone therapy in vivo, the cells phagocytic capability of the blood exposed to ozone was evaluated.

\section{PATIENTS AND METHODS}

In the peripheral blood is possible quantify the phagocytes cells that circulate and to evaluate their phagocytic activity by immunological methods (15). In this study we performed the direct microscopic method of Baehner (16). It is an easy, simple, reproducible analysis and does not require the separation of the neutrophils from the other blood components to evaluate their function.

This study in vitro was performed in several phase: 1. Ozone generation

Ozone was obtained by electrical discharge using an ozone generator (OZOMED Plus, Havana, Cuba), allowing gas flow rate and ozone concentration to be correctly controlled.

2. Collection of human blood

Blood sample $(30 \mathrm{~mL})$ were obtain taken from healthy, no smokers, male blood donor in the morning, heparin $(15 \mathrm{U} / \mathrm{mL}$ blood) was used as anticoagulant, which were immediately subdivided in six glass tubes and introduced $(5 \mathrm{~mL})$ in ozoneresistant syringe. The controls were blood and blood treated with oxygen.

\section{Gas delivery to blood samples}

It was extracted from the ozone generator a predetermined volume $(5 \mathrm{~mL})$ of the $\mathrm{O}_{3} / \mathrm{O}_{2}$ gas mixture at various concentrations $(10,20,40$ and $80 \mu \mathrm{g} / \mathrm{mL}$ ), with a syringe and immediately bubbled into the second syringe containing the samples via a multidirectional stopcock. Based in previous experience, equal blood and gas volume were used (1:1) (1). Samples were gently but continuously mixed with the gas mixture for 10 min. There are experimental evidences in vitro that during this period of time, the ozone reacts completely with substrate (3). To obtain reproducible results $\mathrm{O}_{3}$ required a rapid and precise handling (3).

4- Method to evaluate the phagocytic function:

It was evaluated the cellular function according to Baehner (1968), a direct microscopic method (16), using the latex like an inert particle to be phagocytosed. Values are expressed as a percentage. Also, it was evaluated the viability of leukocytes from the blood treated with ozone respect to their non-treated and oxygen-treated samples using the trypan blue exclusion test and the cells were analyzed by optical microscopy.

5- Statistical analysis

Descriptive statistical

The results were expressed as the mean of phagocytosis (percentage) of neutrophils on the blood.

Inferential statistical

It was calculated the standard deviation of the mean (SD), and the data were analyzed by the paired $\mathrm{T}$ test, $\mathrm{p}$ values less than 0.05 was considered significant.

\section{RESULTS}

Previous studies, performed using washed erythrocytes and suspended in saline solution, showed hemolysis after ozone exposure. Leucocytes of the blood diluted in saline solution and exposed to ozone for 1 hour, have shown some genetic damage (10). In other studies, using isolated human PBMC suspended in commercial human serum that has very low antioxidant capability, has decreased the cellular-proliferation rate at 24 incubation hours with an ozone concentrations of $20 \mu \mathrm{g} / \mathrm{ml}$. However, the direct ozonation of the whole blood has much lower risk of oxidation, due to the human plasma's powerful antioxidant capability that contains hydro and liposoluble antioxidants, growth factors, albumin 
and a large-number of erythrocytes $(17,18)$.

Stimulation of immune cell depends on ozone concentrations used. It has been demonstrated that ozone doses below $10 \mu \mathrm{g} / \mathrm{mL}$ per $\mathrm{mL}$ of blood is ineffective, because is totally neutralized by the plasma antioxidants (18).

Extensive data reported show that ozone doses (range 20-40 $\mu \mathrm{g} / \mathrm{mL}$ ) trigger a controlled and transient oxidative stress able to active several biological processes $(1,19)$. However, it is possible to obtain a lower stimulant activity with increasing ozone concentrations, particularly at 80 $\mu \mathrm{g} / \mathrm{mL}$ per $\mathrm{ml}$ of blood, as we have obtained in this study (decreased value of the phagocytic activity with respect to an ozone concentration of $40 \mathrm{mg} / \mathrm{L}$ ) (figure 1). Several investigations performed to evaluate possible hematochemical or biochemical enzymatic modifications have clearly demonstrated that ozone concentrations of $20-80 \mu \mathrm{g} / \mathrm{ml}$ per $\mathrm{ml}$ of blood do not damage blood cells or other components $(19,20)$.

During the immune response, the cells that have specialized for phagocytic function, primarily macrophages and neutrophils, are the first line of defense against microbes that break epithelial barriers or enter to normal circulation. The

Table 1: Phagocytic function of leucocytes evaluated in blood samples and blood treated with oxygen and different ozone concentrations.

\begin{tabular}{l|cc|cccc}
\hline \multicolumn{3}{c|}{ Control } & \multicolumn{4}{c}{ Blood+Ozone } \\
\hline Phagocytic & Blood & Blood $+\mathrm{O}_{2}$ & $10 \mu \mathrm{g} / \mathrm{mL}$ & $20 \mu \mathrm{g} / \mathrm{mL}$ & $40 \mu \mathrm{g} / \mathrm{mL}$ & $80 \mu \mathrm{g} / \mathrm{mL}$ \\
\cline { 2 - 7 } Function & $30.0 \pm 2.1^{\mathrm{a}}$ & $30.2 \pm 2.1^{\mathrm{a}}$ & $30.8 \pm 2.1^{\mathrm{a}}$ & $36.4 \pm 2.1^{\mathrm{b}}$ & $42.4 \pm 4.2^{\mathrm{c}}$ & $34.2 \pm 3.7 \mathrm{~b}$ \\
\hline
\end{tabular}

Values represent mean $\pm S D(n=5)$.

Different letters represent statistical significance among groups.

Figure 1: Levels of phagocytosis (\%) in human blood samples treated with oxygen and different ozone concentrations.

50

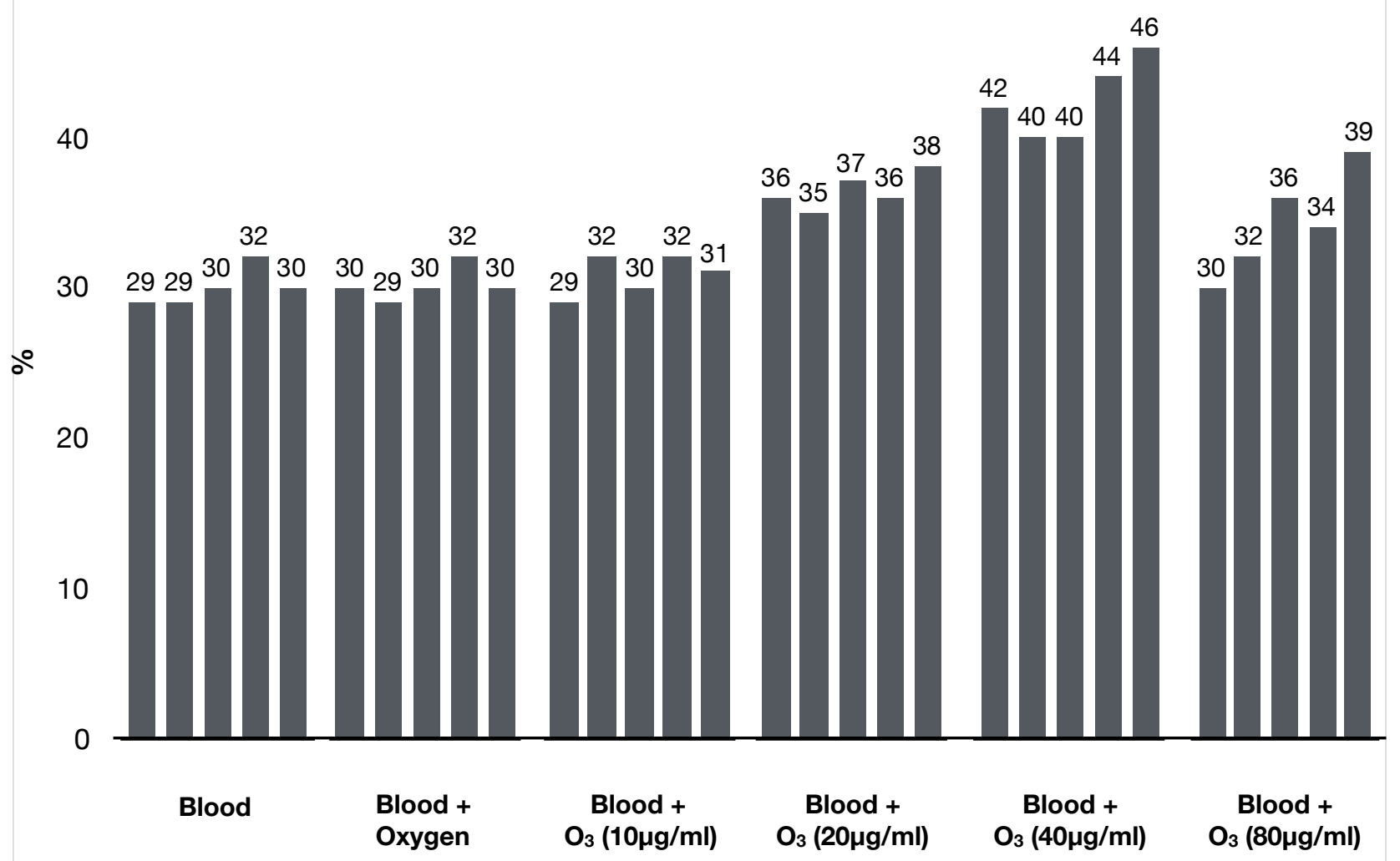


phagocytosis causes the death of microbes by activated phagocytes. In the activated neutrophils, the phagocytized microbes are eliminated by action of anti-microbial molecules in phagolysosomes from the molecular oxygen (13).

The $\mathrm{H}_{2} \mathrm{O}_{2}$ is the main ROS produced during the phagocytosis. It is very useful because is lethal to bacteria, causing their cellular wall lyses, explosion and destruction (13). $\mathrm{H}_{2} \mathrm{O}_{2}$ is a physiological molecule considered essential for the cell life and also because during the oxidative burst is produced for the inactivation of pathogens.

We know the immediate effect that is produced by $\operatorname{ROS}\left(\mathrm{H}_{2} \mathrm{O}_{2}\right)$ rather than by LOPs. $\mathrm{H}_{2} \mathrm{O}_{2}$ is a fundamental messenger, regulates the transduction of signals in the cells. In the leukocytes, it enhances the phagocytic activity (6) and it is responsible of cell activation (8). This can be achieved by either the direct action of $\mathrm{H}_{2} \mathrm{O}_{2}$ over a tyrosine-kinase, with consequent phosphorylation of $\mathrm{Ik}-\mathrm{B}$, one the trimeric components of NF- $\mathrm{kB}$. By this way, the remnant chain, the protein $\mathrm{p} 50 / \mathrm{p} 65$ is translocated to the nucleus, allowing the transcription of several cellular and viral genes including cytokines (19).

It has been evaluated the effects of $\mathrm{H}_{2} \mathrm{O}_{2}$ in the phagocytosis and it was observed that the defensive processes are not capable of destroying the bacteria when there is insufficient formation of $\mathrm{H}_{2} \mathrm{O}_{2}$ (12). There is no doubt that $\mathrm{H}_{2} \mathrm{O}_{2}$ is the trigger as the activation is related to a cysteine oxidation that can be prevented by an excess of thiol (2).

Other results were achieved in an experimental model with bovine blood and showed that ozone administration in vitro had positive effect in bovine PMN of animal with mastitis (20).

Beneficial results reported in clinical trials, using well- performed ozone therapy without side effects was achieved in patient with deficiency in the phagocytic function: the bacterial- infection number decreased, improved health qualitatively and the vitality of the children and also neutrophil phagocytic activity has been found enhanced during ozone therapy (21). Several studies had been instructive to evidence the modulator activity of ozone on the immune system $(12,20,21)$.

On the other hand, it has been reported that human neutrophils are able to generate an ozone-like molecule and volatile compounds as a part of their phagocytic activity (2).

\section{CONCLUSIONS}

In this study it was demonstrated that ozone was able to modulate the phagocytic cells in peripheral blood and the mechanisms on how messengers can activate immunological response leading to the therapeutic biological effects. Furthermore, it was demonstrated that there is a range of ozone concentrations where we can obtain the highest positive results, while lower doses are ineffective and higher doses can produce lower effects. Accordingly, ozone, in a dose-dependent behavior, may stimulate the phagocytic function of the peripheral blood cells.

\section{REFERENCES}

1. Travagli V, Zanardi I, Silvietti A, Bocci V. Physicochemical investigation on the effects of ozone on blood. Int J Biol Macromol 2007; 41: 504-511.

2. Bocci V, Zanardi I, Travagli V. Ozone acting on human blood yields a hormetic dose-response relationship. J Transl Med 2011; 9:66

3. Larini A, Bocci V. Effects of ozone on isolated peripheral blood mononuclear cells. Toxicol in Vitro. 2005; 19: 55-61.

4. Sagai M, Bocci V. Mechanisms of Action Involved in Ozone Therapy: Is healing induced via a mild oxidative stress? Med Gas Res 2011; 1: 29

5. Bocci V, Zanardi I, Travagli V. Oxygen/ozone as a medical gas mixture. A critical evaluation of the various methods clarifies positive and negative aspects. Med Gas Res 2011; 1: 6 .
6. Menéndez S, González R, Ledea OE, León OS, Hernández F, Díaz M. Ozone therapy. Basic aspects and clinical applications. Havana, Cuba: CENIC; 2008.

7. León OS, Menéndez S, Calunga JL, Viebahn R. Ozone oxidative postconditioning reduces oxidative protein damage in patients with Disc Hernia. Neurol Res 2012; 34(1):59-67.

8. Li Q, Verma IM. NF-kB regulation in the immune system. Nature Rev Immunol 2002; 2: 725-734.

9. Bocci V. Ozone as a bioregulator pharmacology and toxicology of ozone today. J. Biol Regul Homeost Agents 1996; 10:31-35.

10. Fukunaga K, Nakazono N, Suzuki T, Takama K. Mechanism of oxidative damage to fish red blood cells by ozone. IUMB Life 1999; 48: 631-634. 
11. Diaz S, Gonzalez Y, Prieto EA, Azoy A. A genotoxic effect of ozone in human peripheral blood leukocytes. Mut Res 2002; 517: 13-20.

12. Volkhovskaya NB, Tkachenko SB, Belopolsky AA. Modulation of phagocytic activity of blood polynuclear leukocytes with ozonized physiological saline. Bull Exp Biol Med 2008; 146(5):559-561.

13. Abbas AK, Lichtman AH, Pober JS. Molecular and cellular immunology. Seven ed. Barcelona: Elsevier; 2012.

14. Aderem A. Underbil DM. Mechanism of phagocytes in macrophages. Ann Rev Immunol 2009; 170:553-623.

15. Locke BA, Dasu T, Verbsky JW. Laboratory Diagnosis of Primary Immunodeficiencies. Clinic Rev Allerg Immunol 2014; 46:154-168

16. Ronald JH, Giclas PC. Diagnostic Immunology Laboratory Manual. New York, USA: Raven Press; 1991.
17. Larini A, Bocci V. Albumin is the most effective antioxidant during human plasma and blood ozonization. Riv Ital OssigenoOzonoterapia 2004; 3: 15-24.

18. Bocci V, Borrelli E, Travagli V, Zanardi I. The ozone paradox: ozone is a strong oxidant as well as a medical drug. Med Res Rev 2009; 29: 646-82.

19. Travagli V, Zanardi I, Bernini P, Nepi S, Tenori L, Bocci V. Effects of ozone blood treatment on the metabolite profile of human blood. Int $\mathbf{J}$ Toxicol 2010; 29:165-74.

20. Tducusin RJ, Kazu M, Sarashina T, Uzaka Y, Tanabe S, Otan.D Phagocytosis of bovine blood and milk polymorph nuclear leukocyte after ozone gas administration in vitro. $\mathrm{J}$ Vet Med Sci 2003; 65(4): 535-539.

21. Díaz J, Sardiñas G, Menéndez S, Macias C. Immumodulatory effect of ozone in children's with deficiency in the phagocytic activity. Mediciego 2012; 18(1). 